\title{
Incidence and risk factors of postpericardiotomy syndrome requiring medical attention: The Finland postpericardiotomy syndrome study
}

\author{
Joonas Lehto, BM, ${ }^{\mathrm{a}}$ Jarmo Gunn, $\mathrm{MD}, \mathrm{PhD},{ }^{\mathrm{a}, \mathrm{b}}$ Pasi Karjalainen, $\mathrm{MD}, \mathrm{PhD}$, \\ Juhani Airaksinen, $\mathrm{MD}, \mathrm{PhD},{ }^{\mathrm{a}}$ and Tuomas Kiviniemi, $\mathrm{MD}, \mathrm{PhD}^{\mathrm{a}}$
}

\begin{abstract}
Objectives: Postpericardiotomy syndrome is a well-known complication after cardiac surgery. Nevertheless, little is known about the incidence and predictors of postpericardiotomy syndrome requiring medical attention or hospitalization in a contemporary set of patients undergoing isolated coronary bypass.
\end{abstract}

Methods: This retrospective analysis included 688 patients from 2008 to 2010 . The median follow-up time was $5.3[4.5-6.0]$ years.

\begin{abstract}
Results: The incidence of postpericardiotomy syndrome was 61 of 688 patients $(8.9 \%)$, and the median time to diagnosis was 21 [11-52] days, but only 13 patients (22\%) required pleural drainage and 3 patients $(4.9 \%)$ required pericardiocentesis. Patients with postpericardiotomy syndrome more often had 1 or more red blood cell units transfused $(61 \%$ vs $43 \%, P=.008)$ after surgery and less often had diabetes $(12 \%$ vs $31 \%$ $P=.002)$ or metformin medication $(3.3 \%$ vs $20 \%, P=.001)$ compared with those without postpericardiotomy syndrome. In multivariable Cox regression model, renal insufficiency and 1 or more red blood cell units transfused remained as independent predictors of postpericardiotomy syndrome and diabetes remained as a protective factor. Incidence of recurrences was high (38\%), and increasing body mass index was the only predictor of relapse.
\end{abstract}

Conclusions: The incidence of symptomatic postpericardiotomy syndrome leading to medical care contact was markedly lower compared with that reported in older clinical studies. Postpericardiotomy syndrome was associated with the use of red blood cell units and was less common in patients with medically treated diabetes. (J Thorac Cardiovasc Surg 2015;149:1324-9)

See related commentary pages $1330-1$.

Postpericardiotomy syndrome (PPS) is a common complication after cardiac surgery. It may lead to prolonged hospital stay, readmissions, and invasive interventions including pericardial or pleural drainage, but the majority of cases have a benign course with mild fever and self-limiting pericardial and pleural effusions. In the literature, the incidence of PPS varies from $10 \%$ to $40 \%,{ }^{1-10}$ and differences in definitions, patient populations, and postdischarge follow-up likely explain this variability and discrepancy. Although recent randomized

From the Heart Center, ${ }^{\text {a }}$ Turku University Hospital and University of Turku, Turku, Finland; Departments of Surgery and Internal Medicine, ${ }^{\mathrm{b}}$ University of Turku, Turku, Finland; and Heart Center, ${ }^{\mathrm{c}}$ Satakunta Central Hospital, Pori, Finland.

This study was supported by grants from the Finnish Foundation for Cardiovascular Research, Helsinki, Finland.

Disclosures: J.A. is a consultant for Bayer AG and Boston Scientific and has received lecture fees from Cardiome Pharma Corp and Boehringer Ingelheim Finland. T.K. has received lecture fees from Bayer AG and AstraZeneca. All other authors have nothing to disclose with regard to commercial support.

Received for publication Oct 11, 2014; revisions received Jan 10, 2015; accepted for publication Jan 18, 2015; available ahead of print Feb 19, 2015.

Address for reprints: Jarmo Gunn, MD, PhD, Heart Center, Turku University Hospital, PL 52, 20521 Turku, Finland (E-mail: jarmo.gunn@tyks.fi).

$0022-5223 / \$ 36.00$

Copyright (C) 2015 by The American Association for Thoracic Surgery

http://dx.doi.org/10.1016/j.jtcvs.2015.01.031 clinical trials, the COlchicine for Prevention of the Postpericardiotomy Syndrome and Postoperative Atrial Fibrillation 1 and 2 , reported $21 \%$ to $29 \%$ incidences of PPS at 3 to 12 months follow-up, little is known about the incidence and predictors of PPS requiring medical attention or hospitalization because of symptoms related to PPS in clinical practice.

In this retrospective "real world" study, we sought to assess the incidence and predictors of PPS requiring medical attention as defined by hospital stay prolongation, readmission, or medical therapy for its treatment.

\section{MATERIAL AND METHODS}

This study is part of a wider protocol in progress to assess thrombotic and bleeding complications of cardiac procedures in Western Finland. ${ }^{11-13}$ Follow-up data were retrieved retrospectively up to 24 months from the surgery from the catchment areas of the Turku University Hospital, the Turku City Hospital, and the Satakunta Central Hospital, Finland. The overall patient population included a consecutive series of 699 patients who underwent isolated coronary artery bypass grafting (CABG) at Turku University Hospital, Finland, from 2008 to 2010. Follow-up data were complete for 688 patients. Hospital records and death certificates from the Statistics Finland were used to acquire data on the mode and date of death. The study protocol was approved by the Ethics Committees of participating hospitals.

\section{Definition of Postpericardiotomy Syndrome and Relapse \\ PPS was defined by the presence of at least 2 of the following criteria: fever without alternative causes, pleuritic chest pain, friction rub, evidence of new}



Abbreviations and Acronyms
$\mathrm{CABG}=$ coronary artery bypass grafting
$\mathrm{CI}=$ confidence interval
HR = hazard ratio
NSAID $=$ nonsteroidal anti-inflammatory drug
PPS = postpericardiotomy syndrome

or worsening pleural effusion, and evidence of new or worsening pericardial effusion. ${ }^{14}$ Relapse was defined by worsening of pericardial or pleural effusion while on medication or after withdrawal of medication.

Diabetes was defined as diabetes requiring medical treatment, pulmonary disease was defined as a lung disease requiring long-term use of bronchodilators or steroids, and stroke was defined as a new neurologic deficit after surgery and lasting more than 24 hours accompanied by new structural changes in computed tomography or magnetic resonance imaging or otherwise verified by clinical assessment. Extracardiac arteriopathy was defined as 1 or more of the following: claudication, carotid occlusion or greater than $50 \%$ stenosis, and previous or planned intervention on the abdominal aorta, limb arteries, or carotid arteries. Recent acute myocardial infarction was defined as an acute myocardial infarction less than 3 months before CABG. Urgent operation was defined as an operation during the same inhospital stay, and emergency operation was defined as an operation before the next working day or within a few hours after angiography. Positive $x-$ ray was defined by new or worsening pleural effusion or new or worsening cardiac silhouette enlargement. Positive electrocardiogram was defined by widespread ST elevations. Postoperative bleeding was defined as bleeding measured in the intensive care unit on the morning of the first postoperative day. Surgical bleeding was defined as a significant bleeding from any anastomosis, graft, or vessel in the surgical field (pericardial artery, thoracic vessels, Keynes veins). The classification of "normal," "abnormal," and "major" use of red blood cell units, fresh-frozen plasma cell units, and platelet units was based on the classification of a wider study in which the patient population of the present study was included. ${ }^{15}$

\section{Statistical Analysis}

Statistical analysis was performed using SPSS statistical software (version 22, IBM SPSS Inc, Armonk, NY). Continuous variables were reported as the mean \pm standard deviation if they were normally distributed and as median [25th, 75th percentiles] if they were skewed. Data were tested for normality assumption using the Kolmogorov-Smirnov and Shapiro-Wilk tests. Categoric variables were described with absolute and relative (percentage) frequencies. Chi-square test, Mann-Whitney test, and Cox regression were used for univariable analysis. The KaplanMeier method was used to present survival curves. Multivariable analysis was performed using the Cox regression method by including variables of relevance. Variables with a $P$ value less than .10 in the univariable analysis were entered in the multivariable analysis.

\section{RESULTS}

\section{Incidence of Postpericardiotomy Syndrome}

The median follow-up time was $5.3 \pm 1.0$ years. Altogether, 61 of 688 patients $(8.9 \%)$ undergoing CABG had PPS leading to delayed hospital discharge, readmission, or medical therapy due to symptoms. The mean latency between operation and hospital admission to PPS was 21 (11-52) days [range, 3-140 days]. Freedom from PPS in patients undergoing isolated CABG is detailed in
Figure 1. Pleuritic chest pain, dyspnea, and fever occurred in $20 \%, 44 \%$, and $41 \%$ of patients with PPS, respectively. Abnormal C-reactive protein values were found in $84 \%$, abnormal erythrocyte sedimentation rate was found in $90 \%$, pericardial effusion was found in $93 \%$, positive chest $\mathrm{x}$-ray was found in $93 \%$, friction rub was found in $6.9 \%$, and positive electrocardiogram was found in $45 \%$ of patients with PPS.

The baseline characteristics and operative data in patients with and without PPS are detailed in Table 1. No differences in the baseline characteristics were detected except that patients with PPS significantly less often had diabetes and were less often taking metformin. Postoperative characteristics in patients with and without PPS are detailed in Table 2. Red blood cell units were significantly more often transfused in the PPS group, and they had a nonsignificant trend toward more postoperative bleeding.

Pleural puncture was performed in 13 patients $(22 \%)$ with PPS, and pericardiocentesis was performed in 3 patients $(4.9 \%)$ with PPS. One patient had PPS leading to clinical cardiac tamponade. No differences in the mortality rates were detected.

\section{Predictors of Postpericardiotomy Syndrome and Relapse}

Cox regression univariable model identified the following variables as predictors of PPS: 1 or more red blood cell units used (hazard ratio [HR], 2.1; 95\% confidence interval $[\mathrm{CI}], 1.3-3.5 ; P=.005)$ and abnormal use of red blood cell units (HR, 1.9; 95\% CI, 1.1-3.4; $P=.016$ ). Diabetes (HR, 0.31;95\% CI, 0.14-0.69; $P=.004$ ) and metformin (HR, $0.14 ; 95 \% \mathrm{CI}, 0.034-0.58$; $P=.006)$ were protective factors. The variables with a $P$ value less than .10 were entered in the multivariable Cox regression analysis. Metformin was excluded because of its association with diabetes, and abnormal use of red blood cell units was excluded because of its association with the use of 1 or more red blood cell units. In multivariable analysis, 1 or more red blood cell units used (HR, 1.9; 95\% CI, 1.1-3.2; $P=.017)$ and decreasing estimated glomerular filtration rate using the Modification of Diet in Renal Disease formula (HR, 0.99; 95\% CI, 0.98-1.0; $P=.078)$ remained as independent predictors of PPS. Diabetes (HR, 0.32; 95\% CI, 0.15-0.71; $P=.005$ ) remained an independent protective factor.

Overall, 23 of 61 patients (38\%) with PPS had a relapse as defined by worsening of pericardial or pleural effusion while on medication or after withdrawal of medication. The baseline characteristics, operative data, symptoms, and clinical findings of patients with relapsed PPS versus patients with nonrelapsed PPS are detailed in Table 3. Patients with relapsed PPS were more obese. The outcome events of relapsed PPS versus nonrelapsed PPS are detailed in Table 4. Patients with relapsed PPS had significantly 


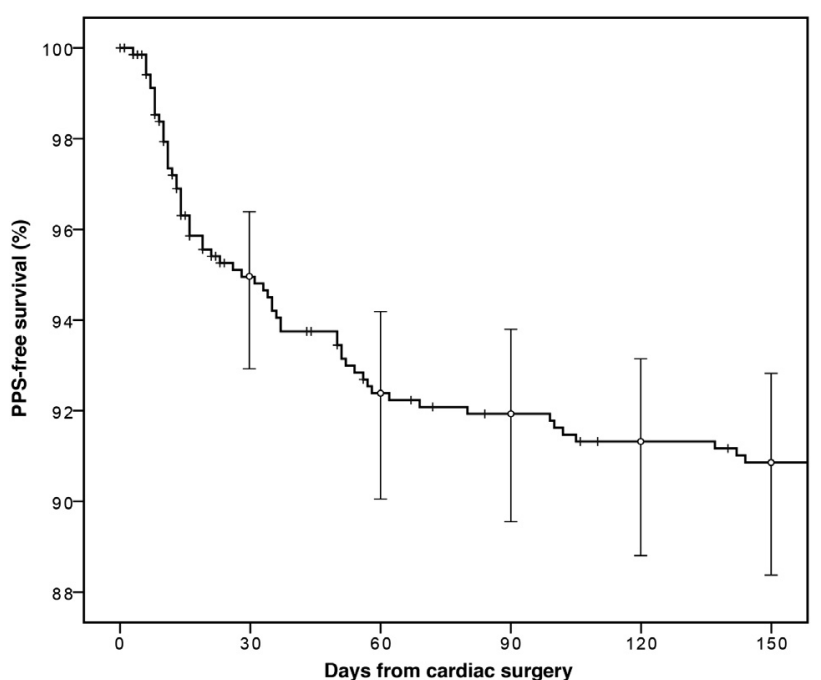

No. of patients at risk

$\begin{array}{llllll}688 & 630 & 609 & 603 & 597 & 593\end{array}$

FIGURE 1. Kaplan-Meier curve with $95 \%$ CIs periodically for the freedom from PPS in patients undergoing isolated CABG. PPS, Postpericardiotomy syndrome.

shorter in-hospital stay after the index $\mathrm{CABG}$ and more pleural punctures due to PPS.

\section{Medication for Postpericardiotomy Syndrome and Relapses}

First-line medication for PPS was glucocorticoids in $43 \%$ of patients, nonsteroidal anti-inflammatory drugs (NSAIDs) in $23 \%$ of patients, and colchicine in $15 \%$ of patients. First-line medications in patients with relapsed PPS and nonrelapsed PPS are detailed in Table 3. There were no significant differences in the first-line medications between relapsed PPS and nonrelapsed PPS cases.

\section{DISCUSSION}

In this "real world" study, the incidence of PPS requiring medical attention was markedly lower compared with incidences reported in recent clinical trials. ${ }^{1,3,4}$ Of note, the clinical course of PPS requiring medical attention was mainly benign, and pericardiocentesis or pleural drainage was performed in only 14 patients $(23 \%)$ with PPS.

This study provides evidence of the association of bleeding and red blood cell use with the occurrence of PPS. Patients with 1 or more red blood cell units used more often had PPS compared with those without. Also, use of abnormal red blood cell units (1-2 units) was a predictor of PPS, but 1 or more red blood cell units used had a stronger presumption against null hypothesis. Thus, the incidence of PPS is presumably not connected to the number of red blood cell units transfused but to the overall use. Surgical trauma and operative effusions have been
TABLE 1. Baseline characteristics and operative data in patients with and without postpericardiotomy syndrome and who underwent isolated coronary artery bypass surgery

\begin{tabular}{|c|c|c|c|}
\hline & $\begin{array}{c}\text { PPS } \\
\mathbf{N}=61\end{array}$ & $\begin{array}{r}\text { No PPS } \\
\mathbf{N}=627 \\
\end{array}$ & $\begin{array}{c}P \\
\text { value }\end{array}$ \\
\hline Age (y) & $67[59,74]$ & $67[60,73]$ & .95 \\
\hline Female & $13(21 \%)$ & $141(23 \%)$ & .83 \\
\hline BMI & $28[25,30]$ & $28[25,31]$ & .32 \\
\hline Diabetes & $7(12 \%)$ & $190(31 \%)$ & .002 \\
\hline Hypertension & $58(95 \%)$ & $590(94 \%)$ & .83 \\
\hline Pulmonary disease & $3(4.9 \%)$ & $49(7.8 \%)$ & .41 \\
\hline Atrial fibrillation & $3(4.9 \%)$ & $49(7.8 \%)$ & .41 \\
\hline $\begin{array}{l}\text { Prior stroke or transient } \\
\text { ischemic attack }\end{array}$ & $3(4.9 \%)$ & $44(7.0 \%)$ & .54 \\
\hline $\begin{array}{l}\text { Prior percutaneous coronary } \\
\text { intervention }\end{array}$ & $10(16 \%)$ & $110(17 \%)$ & .92 \\
\hline Prior cardiac surgery & $0(0.0 \%)$ & $14(2.2 \%)$ & .24 \\
\hline Extracardiac arteriopathy & $1(1.6 \%)$ & $50(8.0 \%)$ & .071 \\
\hline Recent AMI & $14(23 \%)$ & $130(21 \%)$ & .76 \\
\hline 2- or 3-vessel disease & $57(93 \%)$ & $600(96 \%)$ & .34 \\
\hline Left main stenosis & $32(53 \%)$ & $280(44 \%)$ & .20 \\
\hline $\begin{array}{l}\text { Left ventricular ejection } \\
\text { fraction }<30 \%\end{array}$ & $5(8.2 \%)$ & $43(6.9 \%)$ & .70 \\
\hline Emergency operation & $7(12 \%)$ & $94(15 \%)$ & .46 \\
\hline Urgent or emergency operation & $33(54 \%)$ & $320(51 \%)$ & .65 \\
\hline Preoperative IABP & $2(3.3 \%)$ & $5(0.8 \%)$ & .065 \\
\hline Off-pump surgery & $8(13 \%)$ & $71(11 \%)$ & .68 \\
\hline At least 1 thoracic artery graft & $60(98 \%)$ & $600(95 \%)$ & .28 \\
\hline Radial artery graft & $4(6.6 \%)$ & $47(7.5 \%)$ & .79 \\
\hline No. of distal anastomoses & $3.0[2.0,3.0]$ & $3.0[2.0,3.0]$ & .84 \\
\hline \multicolumn{4}{|l|}{ Preoperative laboratory results } \\
\hline INR & $1.0[1.0,1.1]$ & $1.1[1.0,1.1]$ & .054 \\
\hline Hemoglobin & $140[130,150]$ & $140[130,150]$ & .72 \\
\hline Creatinine & $87[77,100]$ & $82[72,95]$ & .068 \\
\hline eGFR & $70[62,83]$ & $77[65,90]$ & .069 \\
\hline \multicolumn{4}{|l|}{ Preoperative drug treatment } \\
\hline Aspirin & $60(98 \%)$ & $580(95 \%)$ & .20 \\
\hline Clopidogrel & $14(23 \%)$ & $100(17 \%)$ & .22 \\
\hline LMWH & $13(21 \%)$ & $160(27 \%)$ & .34 \\
\hline Warfarin & $5(8.2 \%)$ & $52(8.5 \%)$ & .93 \\
\hline Statin & $61(100 \%)$ & $590(95 \%)$ & .074 \\
\hline $\begin{array}{l}\text { Glycoprotein IIa/IIIb } \\
\text { inhibitors }\end{array}$ & $2(3.3 \%)$ & $24(3.8 \%)$ & .83 \\
\hline Thrombolysis & $0(0.0 \%)$ & $17(2.7 \%)$ & .19 \\
\hline Metformin & $2(3.3 \%)$ & $130(20 \%)$ & .001 \\
\hline Sulphonylurea & $1(1.6 \%)$ & $47(7.5 \%)$ & .086 \\
\hline Gliptin & $0(0.0 \%)$ & $8(1.3 \%)$ & .37 \\
\hline Glitazone & $0(0.0 \%)$ & $6(1.0 \%)$ & .44 \\
\hline Insulin & $4(6.6 \%)$ & $85(14 \%)$ & .12 \\
\hline $\begin{array}{l}\text { Aortic crossclamping } \\
\text { time (min) }\end{array}$ & $61[46,71]$ & $59[47,70]$ & .61 \\
\hline CPB time (min) & $80[71,97]$ & $80[67,94]$ & .80 \\
\hline Operation length (min) & $180[150,220]$ & $180[160,210]$ & .58 \\
\hline
\end{tabular}

Continuous variables are reported as median [25th, 75th percentiles]. Values in parentheses are percentages. PPS, Postpericardiotomy syndrome; $B M I$, body mass in$\mathrm{dex} ; A M I$, acute myocardial infarction; IABP, intra-aortic balloon pump; INR, international normalized ratio; $e G F R$, estimated glomerular filtration rate (using Modification of Diet in Renal Disease formula); $L M W H$, low molecular weight heparin; $C P B$, cardiopulmonary bypass. 
TABLE 2. Postoperative characteristics after coronary bypass surgery in patients with and without postpericardiotomy syndrome

\begin{tabular}{|c|c|c|c|}
\hline & $\begin{array}{c}\text { PPS } \\
\mathbf{N}=61\end{array}$ & $\begin{array}{c}\begin{array}{l}\text { No PPS } \\
\mathbf{N}=627\end{array} \\
\end{array}$ & $\begin{array}{c}P \\
\text { value }\end{array}$ \\
\hline IABP & $5(8.2 \%)$ & $47(7.5 \%)$ & .85 \\
\hline Atrial fibrillation & $11(18 \%)$ & $140(23 \%)$ & .41 \\
\hline $\begin{array}{l}\text { Stroke or transient } \\
\text { ischemic attack }\end{array}$ & $1(1.6 \%)$ & $29(4.6 \%)$ & .28 \\
\hline Pneumonia & $3(5.7 \%)$ & $19(3.4 \%)$ & .39 \\
\hline Mediastinitis & $1(1.9 \%)$ & $7(1.2 \%)$ & .69 \\
\hline \multicolumn{4}{|l|}{ Red blood cell } \\
\hline$\geq 1$ units used & $37(61 \%)$ & $270(43 \%)$ & .008 \\
\hline Abnormal use (1-2 units) & $19(31 \%)$ & $120(19 \%)$ & .019 \\
\hline Major use ( $>2$ units) & $18(30 \%)$ & $150(24 \%)$ & .36 \\
\hline \multicolumn{4}{|l|}{ Fresh-frozen plasma } \\
\hline$\geq 1$ units used & $11(18 \%)$ & $99(16 \%)$ & .61 \\
\hline Abnormal use (1-4 units) & $11(18 \%)$ & $88(14 \%)$ & .40 \\
\hline Major use ( $>4$ units) & $0(0.0 \%)$ & $11(1.8 \%)$ & .30 \\
\hline \multicolumn{4}{|l|}{ Platelets } \\
\hline$\geq 1$ units used & $7(12 \%)$ & $70(11 \%)$ & .95 \\
\hline Abnormal use (1-8 units) & $7(12 \%)$ & $56(8.9 \%)$ & .51 \\
\hline Major use ( $>8$ units) & $0(0.0 \%)$ & $14(2.2 \%)$ & .24 \\
\hline Bleeding $(\mathrm{mL})$ & $980[670,1300]$ & $830[620,1200]$ & .099 \\
\hline Resternotomy for bleeding & $4(6.6 \%)$ & $58(9.3 \%)$ & .48 \\
\hline Surgical bleeding & $5(8.2 \%)$ & $25(4.0 \%)$ & .12 \\
\hline ICU stay $(\mathrm{d})$ & $1.0[1.0,2.0]$ & $1.0[1.0,2.0]$ & .89 \\
\hline In-hospital stay (d) & $7.0[6.0,8.0]$ & $7.0[5.0,8.0]$ & .36 \\
\hline
\end{tabular}

Continuous variables are reported as median [25th, 75th percentiles]. Values in parentheses are percentages. Surgical bleeding is a significant bleeding from any anastomosis, graft, or vessel in the surgical field (pericardial artery, thoracic vessels, Keynes veins). $P P S$, Postpericardiotomy syndrome; $I A B P$, intra-aortic balloon pump; $I C U$, intensive care unit.

suggested as potential stimuli for PPS presentation; however, such causality has not been shown.

The incidence of PPS in this study was lower compared with earlier reports $(8.9 \%$ vs $10 \%-40 \%))^{1-10}$ This could be partly attributed to the lack of standardized diagnostic criteria in previous studies. In the current study, however, we used the definition of PPS described in the most recent review article of the diagnostic criteria of PPS. ${ }^{14}$ In prospective studies, the diagnosing of PPS is more sensitive, because the follow-ups are mostly performed by PPS researchers. Thus, the incidence is higher, but the present study implicates that most of the diagnoses are clinically irrelevant. It may also refer to improvements in surgical and cardiopulmonary bypass techniques (eg, smaller bypass circuit and avoidance of cardiotomy suckers). It might also be related to changes in blood transfusion protocols and blood conservation strategies. ${ }^{16}$

In this study, renal insufficiency was associated with PPS. Of note, diabetic patients less often had PPS compared with those without diabetes. Metformin appeared to be the protective factor, although all the other diabetes medications also had a nonsignificant trend toward lesser PPS frequency. A possible mechanism of action of metformin is its effect on the immune system. According to previous studies, high-dose metformin potentiates lymphocyte-suppressing and systemic anti-inflammatory effects of simvastatin and fenofibrate in patients with early glucose metabolism abnormalities. ${ }^{17,18}$ Previously known predictors of PPS were pleural incision and female gender. ${ }^{1}$ Direct pericardial trauma, pericardial bleeding, and individual predisposition are considered to be specific triggers for the syndrome. ${ }^{19}$ In a study released in 1988, lower age, history of prednisone treatment, blood type $\mathrm{B}-$, halothane anesthesia, history of pericarditis, aortic valve replacement, lower weight, higher mean percentages of lymphocytes, and lower platelet counts were predictors of PPS, but the diagnostic criteria were significantly different. ${ }^{5}$ Diabetes was not included in the preoperative data, and the amount of perioperative transfusions did not reach statistical significance.

The incidence of relapses was high $(38 \%)$. In previous studies, recurrences have been reported in approximately $30 \%$ of patients. ${ }^{20,21}$ On the basis of clinical experience and observational reports, aspirin and other NSAIDs are the first-line approach, ${ }^{22,23}$ although the effect of NSAIDs in reducing postoperative pericardial effusion volume is not clear. ${ }^{24}$ The use of NSAIDs was relatively low $(23 \%)$, and the most frequently used first-line medication was glucocorticoids. The high incidence of relapse could be related to the frequent use of glucocorticoids, because according to the latest studies the risk of recurrences of pericarditis is increased by steroid use. ${ }^{20,21}$ In the present study, none of the first-line medications were significantly related to relapse. However, increasing body mass index was a predictor of relapse. In-hospital length of stay after surgery was also significantly shorter, and more pleural punctures due to PPS were performed in the relapsed PPS study group than in the nonrelapsed PPS study group.

The cause of PPS has remained partially unclear. The syndrome has been assumed to be an immune-mediated process, but the role of perioperative infections is unknown ${ }^{25}$ and the participation of immune system is not unequivocal because the syndrome has been present in patients with immunosuppression. ${ }^{26}$ The present study screened preoperative, perioperative, and postoperative factors associated with PPS that could possibly clarify the cause of the syndrome. According to previous studies, preoperative colchicine can significantly decrease the appearance of the syndrome, ${ }^{3,4,21}$ although in the recently published Post-Operative Pericardial Effusion 2 study, colchicine was no better than placebo at reducing the effusion and the risk of cardiac tamponade. A possible clinical implication of the present study is to use preoperative colchicine in patients with predictive factors of PPS. The possible side effects of colchicine thus could be reduced and the number needed to treat consequently lowered. Another possible clinical implication is the use of more aggressive first-line medication for patients with predictors 
TABLE 3. Baseline characteristics and operative data in patients with relapsed postpericardiotomy syndrome and nonrelapsed postpericardiotomy syndrome

\begin{tabular}{|c|c|c|c|}
\hline & $\begin{array}{c}\text { Relapsed } \\
\text { PPS N }=23\end{array}$ & $\begin{array}{l}\text { Nonrelapsed } \\
\text { PPS N }=38\end{array}$ & $\begin{array}{c}P \\
\text { value }\end{array}$ \\
\hline Age (y) & $70[61,74]$ & $66[58,73]$ & .92 \\
\hline Female & $3(13 \%)$ & $10(26 \%)$ & .22 \\
\hline BMI & $29[27,32]$ & $26[25,30]$ & .024 \\
\hline Diabetes & $3(13 \%)$ & $4(11 \%)$ & .77 \\
\hline Hypertension & $22(96 \%)$ & $36(95 \%)$ & .87 \\
\hline Pulmonary disease & $0(0.0 \%)$ & $3(7.9 \%)$ & .17 \\
\hline Atrial fibrillation & $2(8.7 \%)$ & $1(2.6 \%)$ & .29 \\
\hline $\begin{array}{l}\text { Prior stroke or transient } \\
\text { ischemic attack }\end{array}$ & $1(4.3 \%)$ & $2(5.3 \%)$ & .87 \\
\hline $\begin{array}{l}\text { Prior percutaneous coronary } \\
\text { intervention }\end{array}$ & $5(22 \%)$ & $5(13 \%)$ & .38 \\
\hline Prior cardiac surgery & $0(0.0 \%)$ & $0(0.0 \%)$ & - \\
\hline Extracardiac arteriopathy & $1(4.3 \%)$ & $0(0.0 \%)$ & .20 \\
\hline Recent AMI & $7(30 \%)$ & $7(18 \%)$ & .28 \\
\hline 2- or 3-vessel disease & $21(91 \%)$ & $36(95 \%)$ & .60 \\
\hline Left main stenosis & $14(61 \%)$ & $18(47 \%)$ & .31 \\
\hline $\begin{array}{l}\text { Left ventricular ejection } \\
\text { fraction }<30 \%\end{array}$ & $3(13 \%)$ & $2(5.3 \%)$ & .28 \\
\hline Emergency operation & $5(22 \%)$ & $2(5.3 \%)$ & .050 \\
\hline Urgent or emergency operation & $16(70 \%)$ & $17(45 \%)$ & .059 \\
\hline Preoperative IABP & $2(8.7 \%)$ & $0(0.0 \%)$ & .065 \\
\hline Off-pump surgery & $4(17 \%)$ & $4(11 \%)$ & .44 \\
\hline At least 1 thoracic artery graft & $23(100 \%)$ & $37(97 \%)$ & .43 \\
\hline Radial artery graft & $1(4.3 \%)$ & $3(7.9 \%)$ & .59 \\
\hline No. of distal anastomoses & $2.0[2.0,3.0]$ & $3.0[2.0,3.0]$ & .22 \\
\hline \multicolumn{4}{|l|}{ Preoperative laboratory results } \\
\hline INR & $1.0[1.0,1.1]$ & $1.0[1.0,1.1]$ & .49 \\
\hline Hemoglobin & $140[130,150]$ & $140[130,150]$ & .72 \\
\hline Creatinine & $91[84,99]$ & $84[73,100]$ & .27 \\
\hline eGFR & $70[64,78]$ & $73[60,87]$ & .63 \\
\hline \multicolumn{4}{|l|}{ Preoperative drug treatment } \\
\hline Aspirin & $23(100 \%)$ & $37(97 \%)$ & .43 \\
\hline Clopidogrel & $6(26 \%)$ & $8(21 \%)$ & .65 \\
\hline LMWH & $6(26 \%)$ & $7(18 \%)$ & .48 \\
\hline Warfarin & $3(13 \%)$ & $2(5.3 \%)$ & .28 \\
\hline Statin & $23(100 \%)$ & $38(100 \%)$ & - \\
\hline $\begin{array}{l}\text { Glycoprotein IIa/IIIlb } \\
\text { inhibitors }\end{array}$ & $0(0.0 \%)$ & $2(5.3 \%)$ & .26 \\
\hline Thrombolysis & $0(0.0 \%)$ & $0(0.0 \%)$ & - \\
\hline Metformin & $2(8.7 \%)$ & $0(0.0 \%)$ & .065 \\
\hline Sulphonylurea & $1(4.3 \%)$ & $0(0.0 \%)$ & .20 \\
\hline Gliptin & $0(0.0 \%)$ & $0(0.0 \%)$ & - \\
\hline Glitazone & $0(0.0 \%)$ & $0(0.0 \%)$ & - \\
\hline Insulin & $1(4.3 \%)$ & $3(7.9 \%)$ & .59 \\
\hline $\begin{array}{l}\text { Aortic crossclamping time } \\
\text { (min) }\end{array}$ & $52[43,71]$ & $62[55,71]$ & .25 \\
\hline CPB time (min) & $74[60,99]$ & $85[73,94]$ & .32 \\
\hline Operation length (min) & $170[140,210]$ & $180[170,220]$ & .22 \\
\hline \multicolumn{4}{|l|}{ PPS symptoms } \\
\hline Pleuritic chest pain & $6(26 \%)$ & $6(16 \%)$ & .33 \\
\hline Dyspnea & $12(52 \%)$ & $15(40 \%)$ & .33 \\
\hline Fever & $11(48 \%)$ & $14(37 \%)$ & .40 \\
\hline
\end{tabular}

TABLE 3. Continued

\begin{tabular}{lccc}
\hline & $\begin{array}{c}\text { Relapsed } \\
\text { PPS N }=\mathbf{2 3}\end{array}$ & $\begin{array}{c}\text { Nonrelapsed } \\
\text { PPS N }=\mathbf{3 8}\end{array}$ & $\begin{array}{c}\boldsymbol{P} \\
\text { value }\end{array}$ \\
\hline PPS findings & & & \\
$\quad$ Elevated CRP levels & $19(83 \%)$ & $32(84 \%)$ & .87 \\
Elevated ESR levels & $7(100 \%)$ & $13(87 \%)$ & .31 \\
Echocardiography & $21(96 \%)$ & $32(91 \%)$ & .56 \\
Positive chest x-ray & $22(96 \%)$ & $32(91 \%)$ & .54 \\
x-ray: pleural effusion & $19(83 \%)$ & $28(76 \%)$ & .53 \\
x-ray: pericardial effusion & $11(48 \%)$ & $16(43 \%)$ & .73 \\
Friction rub & $1(4.5 \%)$ & $3(8.3 \%)$ & .58 \\
Positive ECG & $9(47 \%)$ & $13(43 \%)$ & .78 \\
First-line PPS medication & & & \\
Starting latency (d) & $1.0[0.0,4.0]$ & $0.0[0.0,4.3]$ & .52 \\
NSAID & $8(35 \%)$ & $6(16 \%)$ & .087 \\
Glucocorticoids & $12(52 \%)$ & $14(37 \%)$ & .24 \\
Colchicine & $2(8.7 \%)$ & $7(18 \%)$ & .30 \\
\hline
\end{tabular}

Continuous variables are reported as median [25th, 75 th percentiles]. Values in parentheses are percentages. PPS, Postpericardiotomy syndrome; $B M I$, body mass index; $A M I$, acute myocardial infarction; $I A B P$, intra-aortic balloon pump; $I N R$, international normalized ratio; $e G F R$, estimated glomerular filtration rate (using the Modification of Diet in Renal Disease formula); $L M W H$, low molecular weight heparin; $C P B$, cardiopulmonary bypass; $C R P, \mathrm{C}$-reactive protein; $E S R$, erythrocyte sedimentation rate; $E C G$, electrocardiography; $N S A I D$, nonsteroidal anti-inflammatory drug.

of relapse. For example, colchicine could be used as firstline medication instead of NSAID in patients with a high risk of relapse.

\section{Study Limitations}

The retrospective nature of this study is a limitation. On the other hand, follow-up was complete for as much as $98 \%$ of the patients because treatment of patients belonging to the catchment area of our institution is mainly centralized. This allowed us to obtain information on major clinical events requiring hospital treatment and information on outpatient visits after surgery because they were performed almost exclusively in tertiary health care. Data on late mortality were obtained from the Statistics Finland, which ensures the quality of survival data of these patients. The small size of this study is another limitation of this analysis; therefore, these findings should be viewed as hypothesis generating. Also, all tests leading to the diagnosis of PPS (eg, chest X-ray and echocardiography) were not performed in every patient, so the underdiagnosing of asymptomatic PPS is conceivable. Nevertheless, the tests were performed as clinically indicated, which reflects the "real world" feature of the present study.

\section{CONCLUSIONS}

The present results suggest that PPS is associated with the use of red blood cell units and is less common in patients with medically treated diabetes. The incidence of PPS was lower and the incidence of relapse was higher when compared with the previous studies.

The authors thank Tommi Kauko, MSc, for statistical advice. 
TABLE 4. Outcome after coronary bypass surgery in patients with relapsed postpericardiotomy syndrome and nonrelapsed postpericardiotomy syndrome

\begin{tabular}{|c|c|c|c|}
\hline & $\begin{array}{c}\text { Relapsed } \\
\text { PPS N }=23\end{array}$ & $\begin{array}{l}\text { Nonrelapsed } \\
\text { PPS } \mathbf{N}=38\end{array}$ & $\begin{array}{c}P \\
\text { value }\end{array}$ \\
\hline IABP & $2(8.7 \%)$ & $3(7.9 \%)$ & .91 \\
\hline Atrial fibrillation & $5(22 \%)$ & $6(16 \%)$ & .56 \\
\hline $\begin{array}{l}\text { Stroke or transient ischemic } \\
\text { attack }\end{array}$ & $1(4.3 \%)$ & $0(0.0 \%)$ & .20 \\
\hline Pneumonia & $1(4.8 \%)$ & $2(6.3 \%)$ & .82 \\
\hline Mediastinitis & $0(0.0 \%)$ & $1(3.1 \%)$ & .41 \\
\hline \multicolumn{4}{|l|}{ Red blood cell } \\
\hline$\geq 1$ units used & $14(61 \%)$ & $23(61 \%)$ & .98 \\
\hline Abnormal use (1-2 units) & $6(26 \%)$ & $13(34 \%)$ & .51 \\
\hline Major use (>2 units) & $8(35 \%)$ & $10(26 \%)$ & .48 \\
\hline \multicolumn{4}{|l|}{ Fresh-frozen plasma } \\
\hline$\geq 1$ units used & $4(17 \%)$ & $7(18 \%)$ & .88 \\
\hline Abnormal use (1-4 units) & $4(17 \%)$ & $7(18 \%)$ & .92 \\
\hline Major use (>4 units) & $0(0.0 \%)$ & $0(0.0 \%)$ & - \\
\hline \multicolumn{4}{|l|}{ Platelets } \\
\hline$\geq 1$ units used & $2(8.7 \%)$ & $5(13 \%)$ & .60 \\
\hline Abnormal use (1-8 units) & $2(8.7 \%)$ & $5(13 \%)$ & .60 \\
\hline Major use (>8 units) & $0(0.0 \%)$ & $0(0.0 \%)$ & - \\
\hline Bleeding (mL) & $990[580,1500]$ & $980[690,1300]$ & .48 \\
\hline Resternotomy for bleeding & $0(0.0 \%)$ & $4(11 \%)$ & .11 \\
\hline Surgical bleeding & $0(0.0 \%)$ & $5(13 \%)$ & .069 \\
\hline ICU stay (d) & $1.0[1.0,2.0]$ & $1.0[1.0,2.0]$ & .72 \\
\hline In-hospital stay (d) & $7.0[6.0,8.0]$ & $8.0[7.0,9.0]$ & .017 \\
\hline $\begin{array}{l}\text { Days from operation to } \\
\text { hospital admission }\end{array}$ & $34[13,57]$ & $15[10,51]$ & .094 \\
\hline Pleural puncture due to PPS & $9(39 \%)$ & $4(11 \%)$ & .010 \\
\hline Pericardiocentesis & $2(8.7 \%)$ & $1(2.6 \%)$ & .29 \\
\hline
\end{tabular}

Continuous variables are reported as median [25th, 75th percentiles]. Values in parentheses are percentages. Surgical bleeding is a significant bleeding from any anastomosis, graft, or vessel in the surgical field (pericardial artery, thoracic vessels, Keynes veins). $P P S$, Postpericardiotomy syndrome; IABP, intra-aortic balloon pump; $I C U$, intensive care unit.

\section{References}

1. Imazio M, Brucato A, Rovere ME, Gandino A, Cemin R, Ferrua S, et al Contemporary features, risk factors, and prognosis of the postpericardiotomy syndrome. Am J Cardiol. 2011;108:1183-7.

2. Finkelstein Y, Shemesh J, Mahlab K, Abramov D, Bar-El Y, Sagie A, et al. Colchicine for the prevention of postpericardiotomy syndrome. Herz. 2002;27: 791-4.

3. Imazio M, Brucato A, Ferrazzi P, Pullara A, Adler Y, Barosi A, et al. Colchicine for Prevention of Postpericardiotomy Syndrome and Postoperative Atrial Fibrillation: the COPPS-2 randomized clinical trial. JAMA. 2014;312: 1016-23.

4. Imazio M, Trinchero R, Brucato A, Rovere ME, Gandino A, Cemin R, et al. COlchicine for the Prevention of the Post-pericardiotomy Syndrome (COPPS): a multicentre, randomized, double-blind, placebo-controlled trial. Eur Heart J. 2010;31:2749-54.
5. Miller RH, Horneffer PJ, Gardner TJ, Rykiel MF, Pearson TA. The epidemiology of the postpericardiotomy syndrome: a common complication of surgery. Am Heart J. 1988;116:1323-9.

6. Kaminsky ME, Rodan BA, Osborne DR, Chen JT, Sealy WC, Putman CE. Postpericardiotomy syndrome. AJR Am J Roentgenol. 1982;138:503-8.

7. Clapp SK, Garson A Jr, Gutgesell HP, Cooley DA, McNamara DG. Postoperative pericardial effusion and its relation to postpericardiotomy syndrome. Pediatrics. 1980;66:585-8.

8. Engle M, Ito T. The postpericardiotomy syndrome. Am J Cardiol. 1961;7:73-82.

9. Janton OH, Golver RP, O'Neill TJ, Gregory JE, Froio GF. Results of the surgical treatment for mitral stenosis; analysis of one hundred consecutive cases. Circulation. 1952;6:321-33.

10. Soloff LA, Zatuchni J, Janton OH, O’Neill TJ, Glover RP. Reactivation of rheumatic fever following mitral commissurotomy. Circulation. 1953;8:481-97.

11. Airaksinen KE, Biancari F, Karjalainen P, Mikkola R, Kuttila K, Porela P, et al Safety of coronary artery bypass surgery during therapeutic oral anticoagulation. Thromb Res. 2011;128:435-9.

12. Biancari F, Myllylä M, Lepojärvi S, Kuttila K, Porela P, Laitio T, et al. Preoperative warfarin treatment and outcome of coronary artery bypass graft surgery Ann Thorac Surg. 2010;89:1139-45.

13. Biancari F, Myllylä M, Porela P, Laitio T, Kuttila K, Satta J, et al. Postoperative stroke in patients on oral anticoagulation undergoing coronary artery bypass surgery. Scand Cardiovasc J. 2011;45:360-8.

14. Imazio M, Brucato A, Ferrazzi P, Spodick DH, Adler Y. Postpericardiotomy syndrome: a proposal for diagnostic criteria. J Cardiovasc Med (Hagerstown). 2013; $14: 351-3$.

15. Mikkola R, Gunn J, Heikkinen J, Wistbacka JO, Teittinen K, Kuttila K, et al. Use of blood products and risk of stroke after coronary artery bypass surgery. Blood Transfus. 2012;10:490-501.

16. Brand A. Immunological aspects of blood transfusion. Blood Rev. 2000;14 130-44.

17. Krysiak R, Gdula-Dymek A, Okopień B. Lymphocyte-suppressing, endothelial-protective and systemic anti-inflammatory effects of metformin in fenofibrate-treated patients with impaired glucose tolerance. Pharmacol Rep. 2013;65:429-34

18. Krysiak R, Okopien B. Lymphocyte-suppressing and systemic anti-inflammatory effects of high-dose metformin in simvastatin-treated patients with impaired fasting glucose. Atherosclerosis. 2012;225:403-7.

19. Imazio M, Spodick DH, Brucato A, Trinchero R, Adler Y. Controversial issues in the management of pericardial diseases. Circulation. 2010;121:916-28.

20. Lotrionte M, Biondi-Zoccai G, Imazio M, Castagno D, Moretti C, Abbate A et al. International collaborative systematic review of controlled clinical trials on pharmacologic treatments for acute pericarditis and its recurrences. Am Heart J. 2010;160:662-70.

21. Imazio M, Bobbio M, Cecchi E, Demarie D, Demichelis B, Pomari F, et al Colchicine in addition to conventional therapy for acute pericarditis: results of the COlchicine for acute PEricarditis (COPE) trial. Circulation. 2005;112: 2012-6.

22. Imazio M, Demichelis B, Parrini I, Giuggia M, Cecchi E, Gaschino G, et al. Day-hospital treatment of acute pericarditis: a management program for outpatient therapy. J Am Coll Cardiol. 2004;43:1042-6.

23. Schifferdecker B, Spodick DH. Nonsteroidal anti-inflammatory drugs in the treatment of pericarditis. Cardiol Rev. 2003;11:211-7.

24. Meurin P, Tabet JY, Thabut G, Cristofini P, Farrokhi T, Fischbach M, et al Nonsteroidal anti-inflammatory drug treatment for postoperative pericardial effusion: a multicenter randomized, double-blind trial. Ann Intern Med. 2010; 152:137-43

25. Imazio M. The post-pericardiotomy syndrome. Curr Opin Pulm Med. 2012;18 366-74.

26. Cabalka AK, Rosenblatt HM, Towbin JA, Price JK, Windsor NT, Martin AB et al. Postpericardiotomy syndrome in pediatric heart transplant recipients. Immunologic characteristics. Tex Heart Inst J. 1995;22:170-6. 